6 - ORIGINAL ARTICLE

ALIMENTARY TRACT

\title{
Medical ozone treatment ameliorates the acute distal colitis in rats $^{1}$
}

\author{
Arif AslanerI, Tuğrul ÇakırI, Seçkin Özgür Tekeli" ${ }^{\text {II }}$ Sema AvcıIII, Uğur Doğan ${ }^{I V}$, Feyza Tekeli ${ }^{\mathrm{V}}$, Hakan Soylü ${ }^{\mathrm{III}}$, Cebrail Akyüz ${ }^{\mathrm{VI}}$, \\ Süleyman Koç ${ }^{\mathrm{VII}}$, İsmail Üstünel ${ }^{\mathrm{VIII}}$, Necat Yılmaz ${ }^{\mathrm{IX}}$
}

DOI: http://dx.doi.org/10.1590/S0102-865020160040000006

IMD, Chief Assistant, Department of General Surgery, Antalya Training and Research Hospital, Antalya, Turkey. Conception, design, intellectual and scientific content of the study.

IIMD, Chief Assistant, Department of Biochemistry, Antalya Training and Research Hospital, Antalya, Turkey. Interpretation of data.

IIIDepartment of Histology and Embryology, Akdeniz University, Antalya, Turkey. Interpretation of data.

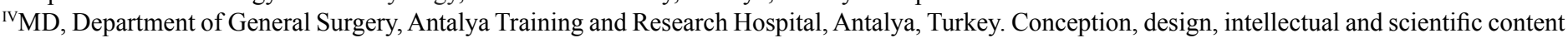
of the study.

'Department of Biochemistry, Antalya Training and Research Hospital, Antalya, Turkey. Interpretation of data.

${ }^{\mathrm{V}} \mathrm{MD}$, Department of Gastroenterology, Haydarpaşa Training and Research Hospital, Istanbul, Turkey. Interpretation of data.

${ }^{\mathrm{VII} D e p a r t m e n t ~ o f ~ G e n e r a l ~ S u r g e r y, ~ I n o n u ̈ ~ U n i v e r s i t y ~ F a c u l t y ~ o f ~ M e d i c i n e, ~ M a l a t y a, ~ T u r k e y . ~ S c i e n t i f i c ~ c o n t e n t ~ o f ~ t h e ~ s t u d y . ~}$

VIIIDepartment of Histology and Embryology, Akdeniz University, Antalya, Turkey. Critical revision.

${ }^{\mathrm{Ix}}$ Department of Biochemistry, Antalya Training and Research Hospital, Antalya, Turkey. Critical revision.

\section{ABSTRACT}

PURPOSE: To investigate the effect of medical ozone treatment on the experimental acute distal colitis in rats.

METHODS: Eighteen rats were randomly distributed into three equal groups; control, acute distal colitis (ADC) without and with medical ozone treatment. Rats in the control group were taken saline. ADC was performed by rectal way with $4 \%$ acetic acid in groups 2 and 3, and the group 3 was treated with medical ozone for three weeks both rectally and intraperitoneally. At the twenty second day the distal colons samples were obtained for malondialdehyde and myeloperoxidase, blood samples were obtained to measure the levels of TNF- $\alpha$ and IL-1 $\beta$ levels. Histolopatological examination was evaluated with Ki-67, IL-1 $\beta$ and VEGF immunostaining densities.

RESULTS: There was significant increase in tissue MDA, MPO activity, TNF- $\alpha$ and IL-1 $\beta$ after ozone administration. There was also a significant difference at immunostaining densities of histopathological examination.

CONCLUSIONS: Medical ozone treatment ameliorated the experimental acute distal colitis induced by acetic acid in rats. Its possible effect is by means of decreasing inflammation, edema, and affecting the proliferation and the vascularization.

Key words: Ozone. Acetic Acid. Colitis. Rats. 


\section{Introduction}

Medical Ozone is described as three atom molecules of oxygen known as $\mathrm{O}_{3}$. Ozone is applied in medical therapy using a gas mixture composed of oxygen and ozone. It is applied in medical therapy using a gas mixture composed of oxygen and ozone. Ozone theraphy has been found useful in the treatment of various diseases including gastroduodenal ulcers, peritonitis, infected wounds, chronic skin ulcers, initial gangrene, burns and colitis ${ }^{1-5}$. It has also been shown that $\mathrm{O}_{3}$ has beneficial effects in the clindamycinassociated enterocolitis model in Djungarian hamsters ${ }^{6}$. Recently, it was reported that ozone theraphy has a preventive effect in experimental models of necrotizing enterocolitis, a caustic esophageal burn model, and acute necrotizing pancreatitis by decreasing tissue damage and increased the antioxidant enzyme activity $^{7-10}$. The concept of using ozone for healing of infected wounds, necrotic or low oxygenated tissue has been studied in orthopaedics, dentistry and skin wounds.

Furthermore the effect of $\mathrm{O}_{3}$ on acute distal colitis at peritonitis in rats and its treatment both via intraperitoneal and rectal route has not been studied before. The aim of this present study was to evaluate the effects of ozone theraphy on healing of distal colitis in a rat model.

\section{Methods}

The experimental procedures were reviewed and approved by Akdeniz University Local Committee on Animal Research Ethics (2015.02.06).

Eighteen adult male Wistar albino rats from Akdeniz University Animal Laboratory (Antalya, Turkey), each weighing 250-300 g were used in this study. They were randomly assigned into three equal groups $(n=6)$ : Control, Acute Distal Colitis (ADC) and ADC with Medical Ozone (MO) groups. The rats maintained at air-conditioned room with a constant temperature $\left(22^{\circ} \mathrm{C}\right)$ with a 12-h light-dark cycle and had free access to food and water.

\section{Experimental design and study groups}

Group 1 was the control group receiving only physiological saline. Group 2 was the acute distal colitis group. Group 3 was the acute distal colitis and medical ozone treated group receiving $1 \mathrm{mg} / \mathrm{kg} /$ day medical ozone (OM-302, Ozone generator, Sedecal, Spain) via both intraperitoneal and rectal route for three weeks at dose of $25 \mathrm{mcg} / \mathrm{ml}$. At the end of the twenty second day the rats were sacrified with decapitation and the distal colonic samples were obtained. The levels of TNF- $\alpha$ and IL-1 $\beta$ from blood serum and, the levels of MDA and MPO from distal colonic tissue samples were analysed. Histopathological analysis was analyzed by an expert pathologist under a light microscope. Two animals did not tolerate the experimental protocol and died during these procedures in group 2 and two more rats were added to study.

All animals were fasted overnight and after 6 hours of fasting, they anesthetized by an intramuscular injection of 50 $\mathrm{mg} / \mathrm{kg}$ ketamine (Ketasol \%10; Richter Pharma AG, Interhas, Ankara, Turkey) and $10 \mathrm{mg} / \mathrm{kg}$ xylazine hydrochloride (Xylazine \%2 Alfasan, Woerden, Holland). The experimental ADC model described by Sharon et al. ${ }^{11}$ was used. The induction of colitis was accomplished by intracolonic administration of $2 \mathrm{~mL}$ of $4 \%$ acetic acid diluted in $0.9 \%$ saline (pH: 2.6) through a polyethylene tube. The tip of the polyethylene tube was inserted $5 \mathrm{~cm}$ into the anus. Acetic acid was slowly administered into the colonic lumen. Following 30 seconds of exposure, excess fluid was withdrawn and the colon was flushed with $2 \mathrm{~mL}$ of $0.9 \%$ serum isotonic saline. Rats in the sham group were subjected to the same procedure, except that isotonic saline was used instead of acetic acid. After the procedure, the rats had free access to oral feeding. The rats received analgesia with acetaminophen (Paracetamol; SigmaAldrich Chemistry, Steinheim, Germany) for pain relieve theraphy in a dose of $50 \mathrm{mg} / \mathrm{kg} / \mathrm{d}$ by oral gavage.

Three week later, the midline incision was performed in all the groups. After the sacrification of rats by decapitation, their abdomens were opened and distal colon tissues were harvested for evaluation. Blood serum samples were obtained by centrifugation.

\section{Tissue preparation}

The frozen distal colon tissues were homogenized in phosphate buffer ( $\mathrm{pH}:$ 7.4) on an ice cube by means of a homogenizator (Heidolph Diax 900; Heidolph Elektro $\mathrm{GmbH}$, Kelhaim, Germany). Homogenates were centrifuged at $7530 \mathrm{~g}$ at $4{ }^{\circ} \mathrm{C}$ for 10 minutes. The protein content of distal colon homogenates and supernatants was measured according to the method described by Lowry et al. ${ }^{12}$.

\section{Laboratory examinations}

The plasma TNF- $\alpha$ and IL- $1 \beta$ levels were analysed using the enzyme-linked immunosorbent assay (ELISA) kits (YH Elisa Biosearch Laboratory, Shanghai, China). These kits were particularly selected because of their high degree of sensitivity, 
specificity and inter-assay and intra-assay precision, and due to requiring a small amount of plasma sample.

Tissue samples were homogenized with ice-cold 150 $\mathrm{mM} \mathrm{KCl}$ for the determination of MDA levels. The MDA levels were assayed by monitoring thiobarbituric acid reactive substance formation as described previously ${ }^{13}$. Lipid peroxidation was expressed in terms of MDA equivalents using an extinction coefficient of $1.56 \times 10^{5} \mathrm{M}^{-1} \mathrm{~cm}^{-1}$ and results are expressed as mmol $\mathrm{MDA} / \mathrm{g}$ protein.

The protein contents of various samples were determined according to the method of Bradford by using bovine serum albumin as a Standard ${ }^{14}$.

MPO activity was measured in tissues in a procedure similar to that documented by Hillegas et al. ${ }^{15}$. Tissue samples were homogenized in $50 \mathrm{mM}$ potassium phosphate buffer $(\mathrm{PB}, \mathrm{pH}$ 6.0 ), and centrifuged at $41.400 \mathrm{~g}$ (10min); pellets were suspended in $50 \mathrm{mM} \mathrm{PB}$ containing $0.5 \%$ hexadecyltrimethylammonium bromide (HETAB). After three freeze and thaw cycles, with sonication between cycles, the samples were centrifuged at 41.400 $\mathrm{g}$ for $10 \mathrm{~min}$. Aliquots $(0.3 \mathrm{ml})$ were added to $2.3 \mathrm{ml}$ of reaction mixture containing $50 \mathrm{mM} \mathrm{PB}$, o-dianisidine, and $20 \mathrm{mM} \mathrm{H}_{2} \mathrm{O}_{2}$ solution. One unit of enzyme activity was defined as the amount of the MPO present that caused a change in absorbance measured at $460 \mathrm{~nm}$ for $3 \mathrm{~min}$. MPO activity was expressed as $\mathrm{U} / \mathrm{g}$ tissue.

\section{Histopathological analysis}

The tissues taken from subjects of each group $(n=6)$ were fixed in $4 \%$ formalin and carried on into paraffin wax. The immunohistochemical staining was performed on sections taken after the paraffin blocking procedure at $5 \mathrm{~mm}$ thickness.

The sections were incubated overnight in $56^{\circ} \mathrm{C}$ incubator, the next morning deparafinization was performed twice with xylene for 10 minutes and dehydrated by passing through 5 minutes each in $100 \%, 90 \%, 80 \%, 70 \%$ alcohol series. The sections were washed in distilled water and washed three times for 5 minutes each in phosphate buffer. In order to eliminate antigenic masking, sections were placed in $0.01 \mathrm{M}$ citrate buffer and were boiled in a microwave oven at $750 \mathrm{~W}$ 't for $4+3$ minutes. Slides were allowed to cool at room temperature for 20 minutes.

After cooling, the sections were treated with PBS for 5 minutes. In order to remove endogenous peroxidase activity, sections were incubated for 20 minutes with 3\% hydrogen peroxide (\# 18312, Sigma Aldrich). In the room temperature and nonspecific humid environment, around of the sections which were washed at PBS were drawn with the hydrophobic pencil, in order to prevent immunoglobulin (Ig) bonding treated with blocking serum (UV blocker Thermo Ultra UV Block, labvisio Corporation Ta-125UB) for 7 minutes.

More of the serum was taken and sections were incubated overnight at $+4^{\circ} \mathrm{C}$ with the primary antibody of proteins; IL$1 \beta$ (sc-7884, rabbit polyclonal IgG-Santa Cruz Biotechnology), 1: 250, VEGF (RS-152, rabbit polyclonal IgG-Santa Cruz Biotechnology), 1: 250, Ki-67 (BS-2130R, rabbit polyclonal IgGBioss antibodies) 1: 250. The isotype controls were applied to the control section instead of the primary antibody. The next day each section was washed with PBS three times for 5 minutes. Then, they were incubated in a humid environment for 45 minutes with biotinylated secondary antibody (biotinylated anti-rabbit $\operatorname{IgG}$ ) 1 : 500 and 20 minutes with HRP-conjugated streptavidin complex (\# 85-9043, Invitrogen) at room temperature. After both applications washing with PBS was performed 3 times for 5 minutes. In order to see the immunostaining density, tissues were developed with Di Amino Benzidine (DAB) chromogen (\# D4168, Sigma) and washed in tap water for 2 minutes. Opposed staining with Mayer's hematoxylin was performed to sections and was closed with Kaiser's gelatin (\# 1.09242.0100; Merck). Sections were examined on Axioplan microscope (Zeiss, Germany) and photographed. In addition, $\mathrm{H} \& \mathrm{E}$ stain is applied to the sections of groups for morphological assessment.

\section{Image J analysis}

The immunohistochemical staining intensity of known photographs images of cross-sections performed by Axioplan microscope (Zeiss, Oberkochen, Germany) were evaluated with the Image J program (http://imagej.nih.gov/ij/). The assessment was performed with each of the five randomly selected preparations immunostained with the Ki-67, IL1- $\beta$ and VEGF. First painted (including Hematoxylin and DAB) determining the appropriate threshold level of the entire area to be masked and then density was measured only DAB positive threshold level to be masked by setting the color density of the region were measured. Staining degree was determined by dividing the DAB positive density to total staining density combination of hematoxylin and DAB and multiplying the result by 100 . As a result; average density ranging from 0 to 100 percent (\%) was expressed as the value.

\section{Statistical analysis}

Statistical analysis was performed by GraphPad Prism 3.0 (GraphPad Software, San Diego, USA). The data were expressed 
as mean \pm standard error of the mean (SEM). Group comparisons were performed with the analysis of variance (ANOVA) followed by Tukey's tests. The data related to immunohistochemical staining intensity of the groups and $\mathrm{J}$ image analysis was compared with the Student's t-test, using Sigma Plot 11.0 (Systat Software, USA). The $p<0.05$ between the groups was considered as statistically significant.

\section{Results}

\section{Results of biochemical analysis}

In the acute distal colitis group, TNF- $\alpha$ levels were significantly increased $(p<0.01)$ when compared to control group, while this acetic acid-induced rise in serum TNF- $\alpha$ level was abolished $(p<0.01)$ with ozone theraphy. Similarly IL-1 $\beta$ levels were also significantly increased in the acute distal colitis group $(p<0.01)$, however when rats were treated with ozone. As a result both cytokines were come closer to control levels. The mean level of MDA was increased in all colonic tissues after sepsis when compared with the control group $(p<0.01)$, while ozone theraphy to the sepsis acute distal colitis group caused a marked decrease in MDA levels $(p<0.01)$. Myeloperoxidase activity was found significantly higher in the distal colonic tissues of the acute distal colitis group when compared to control group $(p<0.01)$. On the other hand, ozone theraphy decreased MPO levels of all tissues $(p<0.01)$, which was found to be not different than that of the control group (Figure 1).
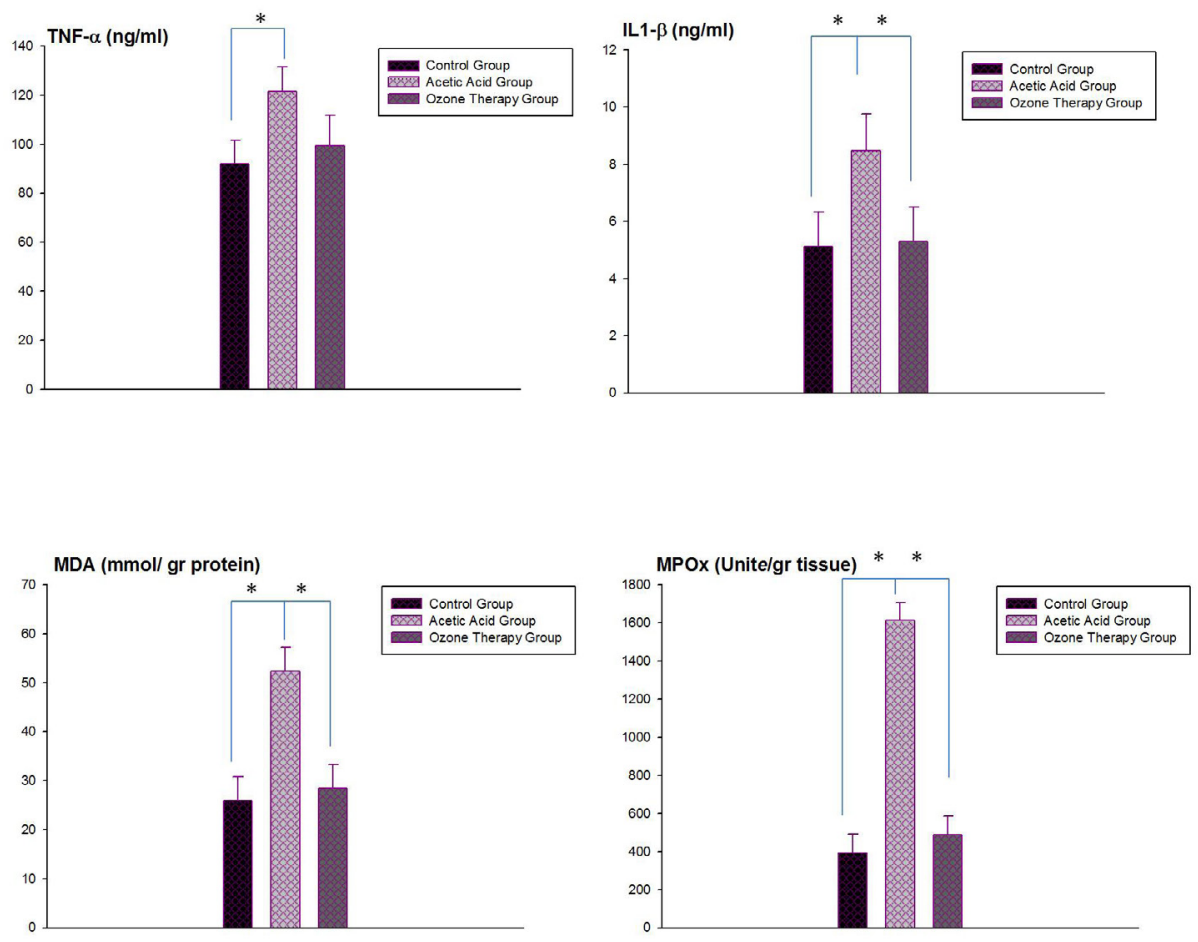

FIGURE 1 - Ozone theraphy effect on TNF- $\alpha$, IL-1 $\beta$, MDA and MPO levels was compared between control, acetic acid and ozone theraphy groups. Each group was consisting of 6 rats. Groups of data were compared with an analysis of variance (ANOVA) followed by Tukey's multiple comparison tests.

\section{Effects of ozone therapy on histopathologic values}

The results of the statistical analysis revealed a statistically significant difference between the control group and the acetic acid group, and also between the acetic acid group and the ozone therapy group (Figure $2, p<0.05$ ). 


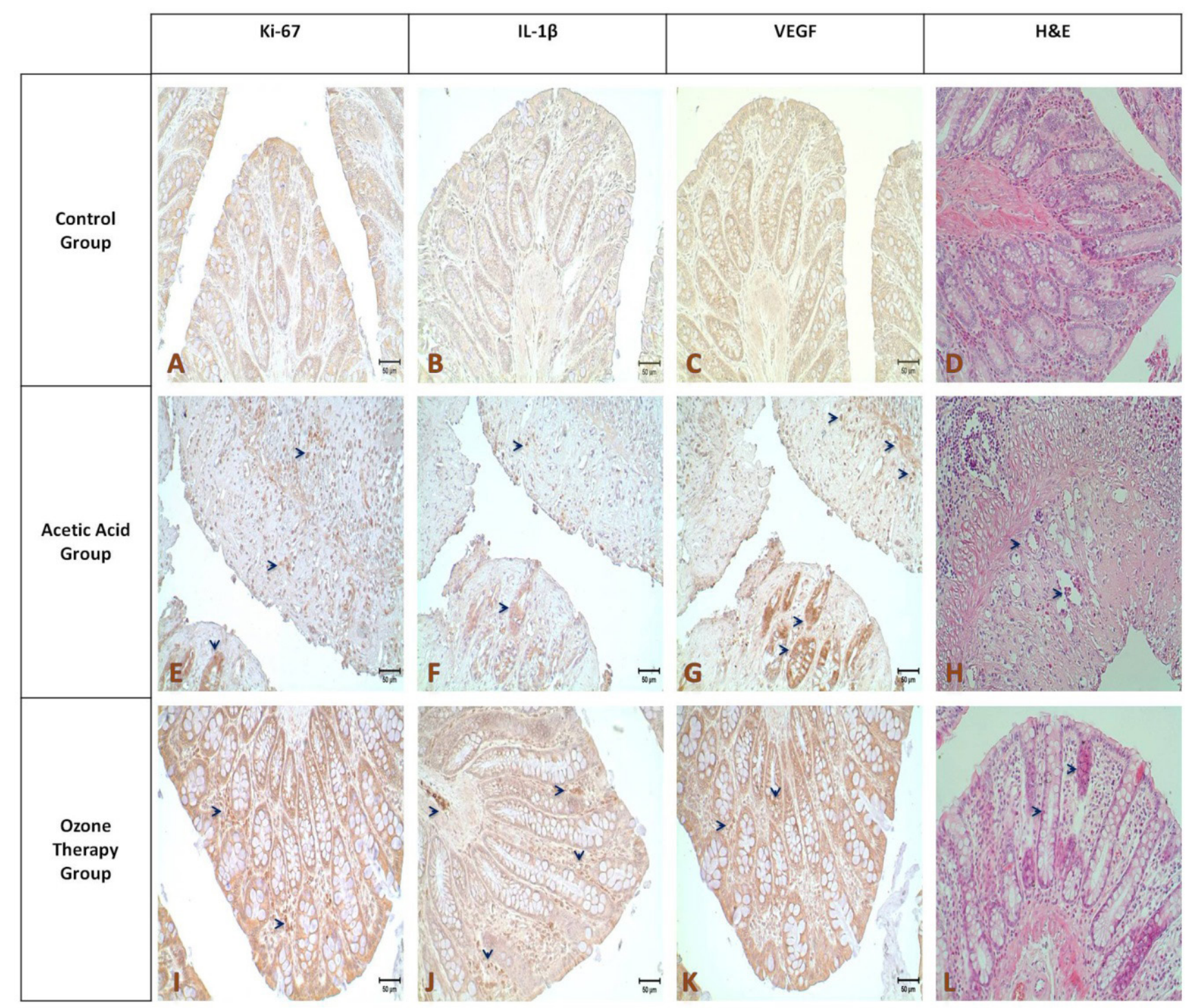

FIGURE 2 - Results of Hematoxylin-eosin staining (A,E,I, x20), compared with the control group administration of acetic acid breaks down the tissue integrity, glandular structures were largely disappeared, it was determined that some removal between the submucosal and muscle layers was occurred (E), In addition, levels of Ki-67, IL-1 $\beta$ and VEGF immunostaining levels are more intense from control group at the tissue affected by the application of acetic acid (F-H; arrows) In the group treated with ozone therapy in addition to the morphological appearance of the glandular structure improvement (I), Ki-67, IL-1 $\beta$ and VEGF staining intensity decreased compared to acetic acid group and come closer to the control levels (J-L).

Immunohistochemical staining intensity in the acetic acid group, compared with the control and ozone therapy group, $\mathrm{Ki}-$ 67 and VEGF in terms of the statistical difference was significant $(p<0.05)$, there is no significant difference between ozone therapy group and control group was found. In terms of IL1- $\beta$, the difference between all groups were evaluated as statistically significantly $(p<0.05)$, While IL1- $\beta$ staining intensity decreases it were observed also high as compared to control group (Figure 3). 

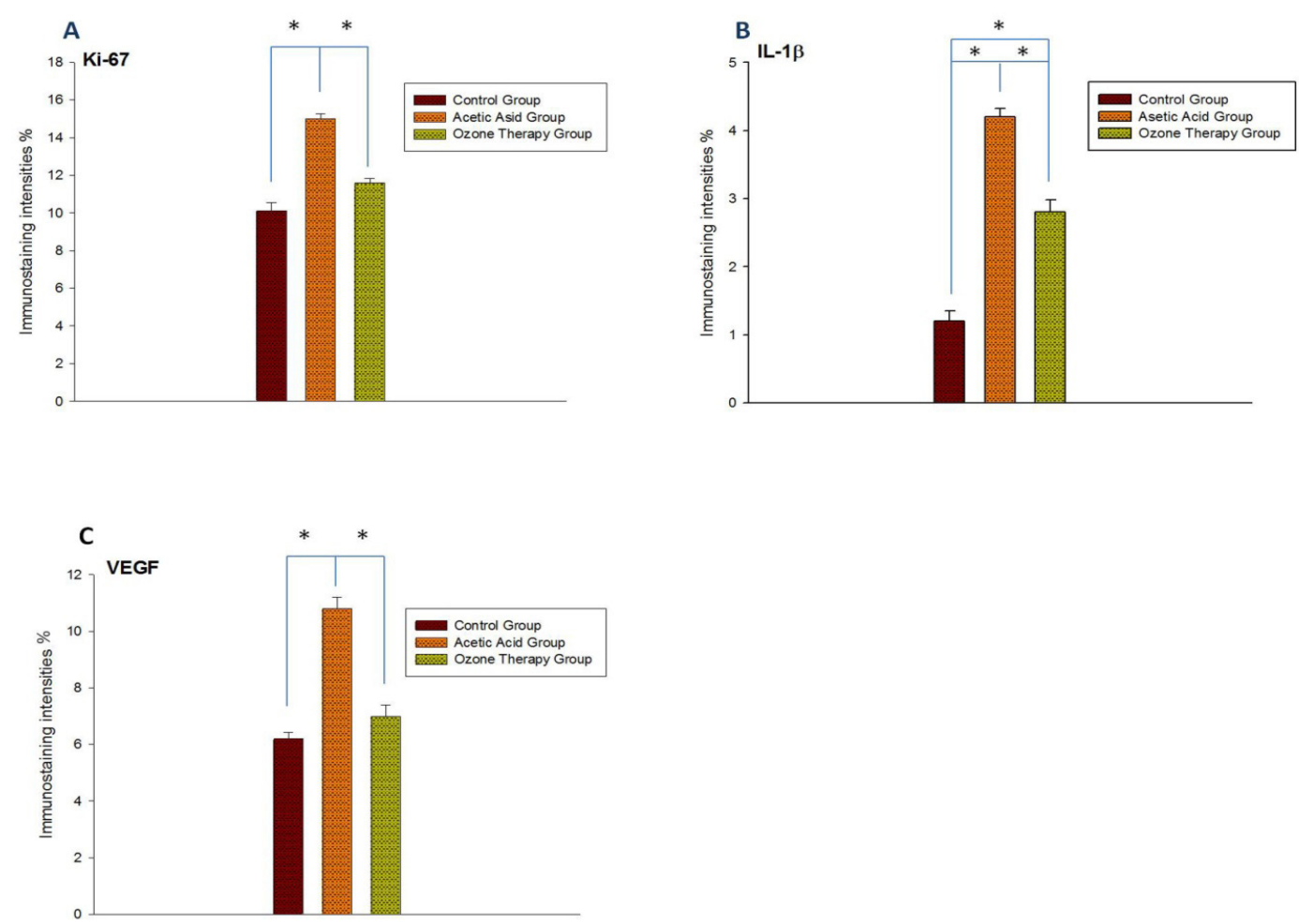

FIGURE 3 - A: Ki-67. B: IL-1ß. C: VEGF. Comparison of immunohistochemical staining intensities between the control, acetic acid and ozone therapy groups.

\section{Discussion}

According to literature search, this is the first study investigating the effect of medical ozone administration both via rectal and intraperitoneally at experimental acetic acid-induced distal colitis model in rats. Findings from our study revealed that distal colitis ameliorated by intraperitoneal and rectal medical ozone administration, while with antioxidant effect the ozone prevented the lipid peroxidation and neutrophil infiltration of the rat colon tissues. The decreasing on tissue MDA levels and MPO activities revealed that ozone theraphy prevented colon tissue from oxidative stress. Also ozone was significantly improved the changes on colonic tissue caused by acetic acid in rats by decreasing the plasma cytokines.

It has been demonstrated that MO supports cellular antioxidant systems includingglutathione, SOD, catalase, and the other enzymatic reactions that prepare the host to encounter physiopathological conditions mediated by $\operatorname{ROS}^{16-20}$. A controlled number and dose of ozone treatments conferred protection against different physiopathological processes mediated by ROS was reported ${ }^{21}$. In a previous study it was reported that ozone exposure altered the levels of inflammatory cytokines, such as tumor necrosis factor $^{22}$ and interleukin ${ }^{23}$. In our study systemic inflammatory response indicators; plasma TNF- $\alpha$ and IL- $1 \beta$ levels were also found increased due to acetic acid administration but decreased by ozone theraphy.

Lipid peroxidation by free oxygen radicals is an important causes of destruction and oxidative damage to cell membranes these containing unsaturated fatty acids, nucleic acids and proteins. The decreasing on tissue MDA levels revealed that ozone theraphy prevented colonic tissue from oxidative damage.

The free oxygen radicals trigger the leukocytes accumulation in colonic tissue and activate neutrophils to secrete enzymes. And this leads to further tissue damage. Therefore, this MPO an enzyme secreted by neutrophils plays role in oxidant production $^{24,25}$. In our study MPO activity which is an index of polimorphonuclear leukocyte infiltration and accumulation was found increased. Increased activities of MPO indicate that contributes to acetic acid induced oxidative distal colon injury in rats. Intraperitoneal and rectal ozone theraphy decreased the MPO activity.

In a present study they showed that ozone theraphy was found more effective in reducing the severity of experimental acute distal colitis than hiperbaric oxygen. Ozone theraphy had an improving effect on oxidant/antioxidant status and a healing effect on the histopathological changes of tissues with acute distal colitis $^{26}$. 
Ozone administration significantly reduced the severity of $\mathrm{ADC}$ in rats. Ozone is 10 times more soluble in water than oxygen $^{27}$. After administration, ozone is dissolved in biological fluids such as plasma, lymph, and urine; it immediately reacts with polyunsaturated fatty acids, antioxidants, reduced glutathione, and albumin. All these compounds act as electron donors and undergo oxidation, resulting in the formation of $\mathrm{H}_{2} \mathrm{O}_{2}$ and lipid oxidation products. An essential ROS molecule, $\mathrm{H}_{2} \mathrm{O}_{2}$ is able to act as an ozone messenger to elicit several biological and therapeutic effects $^{20,28-30}$.

By shifting the oxyhaemoglobin curve into the right, ozone theraphy increased oxygenation of the tissues. $\mathrm{H}_{2} \mathrm{O}_{2}$ formed by the OT causes the production of many growth factors, especially $V_{E G F}{ }^{31}$. In the current study, we evaluated VEGF expression and according to the histopathological results we found a statisticaly significant difference on immunostaining densities of Ki-67, VEGF and IL1- $\beta$ between the control-acute distal colitis groups and ADC-ozone therapy group.

One of the limitations of the study is having no antibiotic application.

In our study as a result, intraperitoneally and rectally performed ozone theraphy in acute distal colitis model with acetic acid was significantly reduced the plasma TNF- $\alpha$ and IL$1 \beta$ levels, MDA levels and MPO activity, and also ameliorated the histological changes in tissue. As well as, we conclude that the impact of ozone therapy is thought to be associated with a reduction in the levels of TNF- $\alpha$ and IL- $1 \beta$.

\section{Conclusion}

Preconditioning with $\mathrm{O}_{3}$ intraperitoneally and treatment with rectal route might protect the distal colon against distal colitis in rats induced by acetic acid by decreasing edema, inflammation affecting the proliferation and the vascularization at the tissue.

\section{References}

1. Kose E, Sapmaz HI, Sarihan E, Vardi N, Turkoz Y, Ekinci N. Beneficial effects of montelukast against methotrexate-induced liver toxicity: a biochemical and histological study. Sci World J. 2012;2012:987508. doi: 10.1100/2012/987508.

2. Braun J, Rau R. An update on methotrexate. Curr Opin Rheumatol. 2009 May;21(3):216-23. doi: 10.1097/BOR.0b013e328329c79d.

3. Soliman ME. Evaluation of the possible protective role of folic acid on the liver toxicity induced experimentally by methotrexate in adult male albino rats. Egypt J Histol. 2009;32:118-28.

4. Oter S, Korkmaz A. Relevance of hyperbaric oxygen to ozone therapy. Arch Med Res. 2006 Oct;37(7):917-8; author reply 919. PMID: 16971237.

5. Re L, Mawsouf MN, Menéndez S, León OS, Sánchez GM,
Hernández F. Ozone therapy: clinical and basic evidence of its therapeutic potential. Arch Med Res. 2008 Jan;39(1):17-26. PMID: 18067991.

6. Eliakim R, Karmeli F, Rachmilewitz D, Cohen P, Zimran A. Ozone enema: a model of microscopic colitis in rats. Dig Dis Sci. 2001 Nov;46(11):2515-20. PMID: 11713963.

7. Durak I, Yurtarslanl Z, Canbolat O, Akyol O. A methodological approach to superoxide dismutase (SOD) activity assay based on inhibition of nitroblue tetrazolium (NBT) reduction. Clin Chim Acta. 1993 Jan 31;214(1):103-4. PMID: 8453769.

8. Uysal B, Yasar M, Ersoz N, Coskun O, Kilic A, Cayc T, Kurt B, Oter S, Korkmaz A, Guven A. Efficacy of hyperbaric oxygen therapy and medical ozone therapy in experimental acute necrotizing pancreatitis. Pancreas. 2010 Jan;39(1):9-15. doi: 10.1097/ MPA.0b013e3181bb5ae3.

9. Guven A, Gundogdu G, Sadir S, Topal T, Erdogan E, Korkmaz A, Surer I, Ozturk H. The efficacy of ozone therapy in experimental caustic esophageal burn. J Pediatr Surg. 2008 Sep;43(9):1679-84. doi: 10.1016/j.jpedsurg.2008.01.064

10. Guven A, Gundogdu G, Vurucu S, Uysal B, Oztas E, Ozturk $\mathrm{H}$, Korkmaz A. Medical ozone therapy reduces oxidative stress and intestinal damage in an experimental model of necrotizing enterocolitis in neonatal rats. J Pediatr Surg. 2009 Sep;44(9):17305. doi: 10.1016/j.jpedsurg.2009.01.007.

11. Sharon P, Stenson WF. Metabolism of arachidonic acid in acetic acid colitis in rats. Similarity to human inflammatory bowel disease. Gastroenterology. 1985 Jan;88(1 Pt 1):55-63. PMID: 3917261.

12. Lowry $\mathrm{OH}$, Rosebrough NJ, Farr AL, Randall RJ. Protein measurement with the Folin phenol reagent. J Biol Chem. 1951 Nov;193(1):265-75. PMID: 14907713

13. Dalaklioglu S, Genc GE, Aksoy NH, Akcit F, Gumuslu S. Resveratrol ameliorates methotrexate-induced hepatotoxicity in rats via inhibition of lipid peroxidation. Hum Exp Toxicol. 2013;32:66271. doi: 10.1177/0960327112468178.

14. Chládek J, Martínková J, Sispera L. An in vitro study on methotrexate hydroxylation in rat and human liver. Physiol Res. 1997;46(5):3719. PMID: 9728483.

15. Bulynin VI, Glukhov AA. Treatment of peritonitis using ozone and hydropressive technology. Khirurgiia (Mosk). 1999;(7):9-11. PMID: 10459177.

16. Reth M. Hydrogen peroxide as second messenger in lymphocyte activation. Nat Immunol. 2002 Dec;3(12):1129-34. PMID: 12447370.

17. Chen H, Xing B, Liu X, Zhan B, Zhou J, Zhu H, Chen Z. Similarities between ozone oxidative preconditioning and ischemic preconditioning in renal ischemia/reperfusion injury. Arch Med Res. 2008 Feb;39(2):169-78. doi:10.1016/j.arcmed.2007.09.005.

18. Madej P, Plewka A, Madej JA, Nowak M, Plewka D, Franik G, Golka D. Ozonotherapy in an induced septic shock. I. Effect of ozonotherapy on rat organs in evaluation of free radical reactions and selected enzymatic systems. Inflammation. 2007 Apr;30(12):52-8. PMID: 17372841.

19. Ajamieh H, Merino N, Candelario-Jalil E, Menéndez S, MartinezSanchez G, Re L, Giuliani A, Leon OS. Similar protective effect of ischaemic and ozone oxidative preconditionings in liver ischaemia/ reperfusion injury. Pharmacol Res. 2002 Apr;45(4):333-9. PMID: 12030798.

20. Zamora ZB, Borrego A, López OY, Delgado R, González R, Menéndez S, Hernández F, Schulz S. Effects of ozone oxidative preconditioning on TNF-alpha release and antioxidant-prooxidant intracellular balance in mice during endotoxic shock. Mediators Inflamm. 2005 Feb 24;2005(1):16-22. PMID: 15770062.

21. León OS, Menéndez S, Merino N, Castillo R, Sam S, Pérez L, Cruz E, Bocci V. Ozone oxidative preconditioning: a protection against 
cellular damage by free radicals. Mediators Inflamm. 1998;7(4):28994. PMID: 9792340.

22. Paulesu L, Luzzi E, Bocci V. Studies on the biological effects of ozone: 2. Induction of tumor necrosis factor (TNF-alpha) on human leucocytes. Lymphokine Cytokine Res. 1991 Oct;10(5):409-12. PMID: 1768744.

23. Bocci V, Valacchi G, Corradeschi F, Fanetti G. Studies on the biological effects of ozone: 8 . Effects on the total antioxidant status and on interleukin-8 production. Mediators Inflamm. 1998;7(5):3137. PMID: 9883965.

24. Winterbourn CC, Vissers MC, Kettle AJ. Myeloperoxidase. Curr Opin Hematol. 2000 Jan;7(1):53-8. PMID: 10608505.

25. Donnahoo KK, Meng X, Ayala A, Cain MP, Harken AH, Meldrum DR. Early kidney TNF-alpha expression mediates neutrophil infiltration and injury after renal ischemia-reperfusion. Am J Physiol. 1999 Sep;277(3 Pt 2):R922-9. PMID: 10484513.

26. Altinel O, Demirbas S, Cakir E, Yaman H, Ozerhan IH, Duran E, Cayci T, Akgul EO, Ersoz N, Uysal B, Kurt B, Yasar M, Oter S, Peker Y. Comparison of hyperbaric oxygen and medical ozone therapies in a rat model of experimental distal colitis. Scand J Clin Lab Invest. 2011 May;71(3):185-92. doi:10.3109/00365513.2010.

27. Bocci V, Aldinucci C. Biochemical modifications induced in human blood by oxygenation-ozonation. J Biochem Mol Toxicol. 2006;20(3):133-8. PMID: 16788956.

28. Bocci VA. Scientific and medical aspects of ozone therapy. State of the art. Arch Med . 2006;37(4):425-35. PMID: 16624639.

29. Bocci V. Ozone as Janus: this controversial gas can be either toxic or medically useful. Mediators Inflamm. 2004 Feb;13(1):3-11. PMID: 15203558

30. Halliwell B, Clement MV, Long LH. Hydrogen peroxide in the human body. FEBS Lett. 2000 Dec 1;486(1):10-3. PMID: 11108833.
31. Tandara AA, Mustoe TA. Oxygen in wound healing more than a nutrient. World J Surg. 2004 Mar;28(3):294-300. PMID: 14961188.

\section{Acknowledgement}

To Dr. Başar ŞENYÜZ for ozone supply from Ozonklinik Antalya Turkey.

\section{Correspondence:}

\section{Arif Aslaner}

Antalya Taining and Research Hospital Transplantation and General Surgery Department 070100, Antalya, Turkey Phone: +902422494400-3381

Gsm: +90 5314309987

Fax: +90 2422494462

arifaslaner@gmail.com

Received: Dec 08, 2015

Review: Feb 10, 2016

Accepted: Mar 11, 2016

Conflict of interest: none

Financial source: none

${ }^{1}$ Research performed at Research Laboratory, Akdeniz University of Medicine, Antalya, Turkey. 